- Sự khác biệt nồng độ dopamine huyết tương giữa xét nghiệm lần thứ 1 và lần thứ 2; giữa xét nghiệm lần thứ 1 và nhóm chứng có ý nghĩa thống kề với; sự khác biệt giữa xét nghiệm lần thứ 2 và nhóm chứng không có ý nghĩa thống kê.

\section{TÀI LIÊU THAM KHẢO}

1. Sadock B.J., Sadock V.A. (2008). "Schizophrenia", Concise textbook of clinical psychiatry, Third edition, William and Wilkins, pp. 156-177.

2. Trinh Văn Anh (2017). Nghiên cứu đăc điểm dich tể học lâm sàng rối loạn tâm thân ở bệnh nhân tự sát. Luạân án tiến sỹ, Học viện Quân Y, Hà Nội.

3. Nguyển Thanh Bình (2010). Nghiên cứu đặc điểm lâm sàng và nồng độ Dopamine huyết tương ở bệnh nhân tâm thần phẩn liệt thể paranoid. Luận án tiến sỹ, Học viện Quân Y, Hà Nội.

4. Rao M.L., Gross G., Halaris A. et al. (1993). "Hyperdopaminergia in schizophreniform psychosis: a chronobiological study", Psychiatry Res, May, 47(2), pp. 187-203.

5 . Dávila R., Zumárraga M., Basterreche N. et al. (2007). "Plasma homovanillic acid levels in schizophrenic patients: correlation with negative symptoms", Psychiatry Res., 30; 151(1-2), pp. 163-168.

6. Z.J.Zhang, M.Peet, C.N.Ramchand et al., (2001). "Plasma homovanillic acid in untreated schizophrenia - relationship with symptomatology and sex", Journal of Psychiatric Research, Volume 35 , Issue 1 , pp. 23-28.

\title{
ĐÁNH GIÁ SỰ TUÂN THỦ SỬ DỰG THUỐC LEVOTHYROXINE Ở BỆNH NHÂN SUY GIÁP TIÊN PHÁT CAO TUỔI TẠI BỆNH VIỆN HỮU NGHI!
}

\section{TÓM TẮT}

Mục tiêu: Xác định tỉ lệ tuân thủ sử dụng thuốc Levothyroxine (L-T4) và các yếu tố liên quan ở bệnh nhân suy giáp tiên phát (SGTP) cao tuổi tại phò̀ng khám Nội tiết, bệnh viện Hữu Nghị. Đối tượng và phương pháp nghiên cứu: nghiên cứu mổ tả cắt ngang trên 82 bênh nhân suy giáp tiên phát, tuổi từ 60 đến 87, tham gia khám bệnh tại phòng khám Nội tiết, bênh viên Hữu Nghi từ 8/2020 đến 8/2021. Các xét nghiệm được tiến hành gôm TSH, FT4. Kết quả và bàn İuân: Có $85,4 \%$ bênh nhân tuân thủ điều trị thuốc (TTĐTT). Mức độ TTĐTT: cao 69,5\%; trung bình 15,9\%; thấp $14,6 \%$. Có $78,1 \%$ đat muc tiêu điều trị (bình giáp), 21,9\% chưa đạt mục tiêu điều trị. Các yểu tố liên quan đến tỉ lê tuân thủ điều tri L-T4 là trình đô hoc vấn $(\mathrm{OR}=11,8 ; 95 \% \mathrm{CI}: 2,6-54,3)$ và muc tiểu điều trị (OR=4,8,95\% CI:1,3-17,6). Kết luân: Tỷ lệ tuân thủ sử dụng thuốc L-T4 trên bệnh nhân suy giáp tiên phát cao tuổi chiếm khoảng $85,4 \%$. Các yếu tố liên quan đến tuân thủ sử dụng thuốc L-T4: Trình độ học vấn và mục tiêu điều trị. Kiến nghị: hướng dẩn bệnh nhân tham khảo các tài liệu, sách báo, tạp trí, internet cùng sự hướng dẫn của nhân viên y tế về bênh suy giáp.

Tư khóa: Tuân thủ điều trị thuốc, suy giáp tiên phát, Levothyroxine.

\section{SUMMARY}

\footnotetext{
${ }^{1}$ Bệnh viện Hữu nghị

²Bênh viện Bach Mai,

${ }^{3}$ Trường đại hoc Y Hà Nôi

Chịu trách nhiệm chính: Phạm Thị Hằng

Email: minhhangpham87@gmail.com

Ngày nhận bài: 12.8.2021

Ngày phản biên khoa hoc: 8.10 .2021

Ngày duyệt bài: 14.10.2021
}

\author{
Phạm Thị Hằng ${ }^{1}$, Nguyễn Quang Bảy ${ }^{2,3}$
}

\section{ASSESSMENT OF COMPLIANCE WITH LEVOTHYROXINE IN ELDERLY PATIENTS WITH HYPOTHYROIDISM AT FRIENDSHIP HOSPITAL}

Objective: To determine the rate of adherence to using Levothyroxine (L-T4) and related factors in elderly patients with primary hypothyroidism at the Endocrinology clinic, Huu Nghi hospital. Subjects and methods: a cross-sectional descriptive study on 82 primary hypothyroidism patients, aged 60 to 87 years, who attended the medical examination at the Endocrine Clinic, Huu Nghi Hospital from August 2020 to August 2021. Tests were conducted including TSH, FT4. Results and discussion: $85.4 \%$ of patients adhered to drug treatment. Level of information communication: high 69.5\%; average $15.9 \%$; as low as $14.6 \%$. There were $78.1 \%$ reaching the treatment target (Euthyroid), 21.9\% not reaching the treatment goal. The factors related to the L-T4 adherence rate were education level $(\mathrm{OR}=11.8 ; 95 \% \mathrm{CI}$ : 2.6-54.3) and treatment goals $(\mathrm{OR}=4.8)$. , 95\% CI: 1.3-17.6). Conclusion: The rate of adherence to using L-T4 in elderly primary hypothyroidism patients is about $85.4 \%$. Factors related to adherence to L-T4 drug use: Education level and treatment goals. Recommendations: instruct patients to refer to documents, books, magazines, the internet and the guidance of medical staff about hypothyroidism.

Keywords: Drug adherence, primary hypothyroidism, Levothyroxine.

\section{I. ĐĂT VẤN ĐỀ}

Suy giáp(SG) là một trong những rối loạn nội tiết phố biến nhất, ảnh hưởng đến $10 \%$ dân số toàn câu[1]. Tại Việt Nam, bệnh SG khá thường gặp, tỷ lệ mắc bệnh này tăng theo tuổi. SG có nhiều nguyên nhân khác nhau và thường phải điều trị lâu dài. Nếu điều trị tốt thì chất lượng 
cuộc sống tốt, tuổi thọ bình thường. Nhiều nghiên cứu cho thây tỷ lệ bệnh nhân tuân thủ kém, bệnh nhân có chế độ ăn đặc biệt, hoặc tương tác thuốc, nên có thể liều L-T4 không đủ hoặc thưa, dẫn đến nhiếm độc giáp, hoặc vẫn SG [2]. Tại bệnh viện Hữu Nghị, đối tượng bệnh nhân chủ yếu là người cao tuổi, thường có nhiều bệnh đi kèm, phải dùng nhiêu thuốc, có thể ý thức không minh mẫn, phải phụ thuộc vào con cháu, nên việc tuân thủ điểu trị có thể kém hoặc có tương tác thuốc, làm ảnh hưởng đến kết quả điều trị. Vì vậy chúng tôi tiến hành đề tài: "Đánh giá sự tuân thủ sử dụng thuốc Levothyroxine ở bệnh nhân suy giáp tiên phát cao tuổi tại Bệnh viện Hữu Nghị" với các mục tiêu sau:

1. Xác định tỉ lệ tuân thủ sử dụng thuốc Levothyroxine ở bệnh nhân suy giáp tiên phát cao tuổi tại phòng khám Nội tiết, bệnh viện Hữu Nghị.

2. Xác định các yếu tố liên quan tuân thư sử dụng thuốc Levothyroxine ở bệnh nhân suy giáp tiên phát cao tuôi tại phòng khám Nội tiêt, bệnh viện Hữu Nghị.

\section{II. ĐỐI TƯỢNG VÀ PHƯƠNG PHÁP NGHIÊN CỨU}

2.1. Đối tượng nghiên cứu. Gồm 82 bệnh nhân SGTP đã đến khám và điều trị tại phò̀ng khám Nội tiết, Bệnh viện Hữu Nghị trong thời gian từ tháng 8 năm 2020 đến tháng 8 năm 2021.

\subsubsection{Tiêu chuẩn lựa chọn}

- Đã được chẩn đoán xác định SGTP theo tiêu chuẩn của Wilmar M. Wiersinga (2004) [3].
- Điêu trị bằng thuốc L-T4 ít nhất 2 tháng tại Bệnh viện Hữu Nghị.

- Bệnh nhân $\geq 60$ tuổi.

- Bệnh nhân có khả năng đọc, nghe, có khả năng giao tiếp.

- Đồng ý tham gia nghiên cứu.

2.1.2. Tiêu chuẩn loại trừ

- SG thứ phát, SG thoáng qua, không dùng hormon giáp.

- SG do sau mổ ung thư tuyến giáp.

- Đang mắc bệnh cấp tính.

\section{2. Địa điểm và thời gian nghiên cứu}

- Từ tháng 7/2020 đến tháng 10/2021 tại Bệnh viện Hữu Nghị.

\subsection{Phương pháp nghiên cứu:}

- Thiết kế nghiên cứu: Nghiên cứu mô tả cắt ngang.

- Cõ̃ mẫu: Toàn bộ. Mỗi bệnh nhân chỉ được lấy 1 lần duy nhất là lần khám đầu tiên trong thời gian nghiên cứu.

- Chọn mẫu thuận tiện.

\subsection{Phương pháp và công cụ thu thập} số liệu

Nhóm nghiên cứu khai thác các dữ kiện sau:

- Tuổi, giới, trình độ học vấn.

- Số bệnh đồng mắc, số loại thuốc sử dụng.

- Thời gian điều trị L-T4.

- Xét nghiệm TSH, FT4.

- Đánh giá sự TTSDT thuốc L-T4 bằng bộ câu hỏi Morisky 8 câu hỏi.

\section{Bảng 1: Bộ câu hỏi Morisky-8 (MMAS-8) [4]}

\begin{tabular}{|c|c|c|}
\hline Câu hỏi & \multicolumn{2}{|c|}{ Trả lời } \\
\hline 1. Ông/bà có thường xuyên quên uống thuốc L-T4 không? & Có & Không \\
\hline 2. Trong 2 tuân qua, ông/bà có quên thuốc L-T4 ngày nào không? & Có & Không \\
\hline $\begin{array}{l}\text { 3. Trong } 2 \text { tuân qua, khi uống thuốc L-T4 mà thấy khó chịu, ông/bà có tự ý dừng } \\
\text { thuốc lẩn nào không? }\end{array}$ & Có & Không \\
\hline $\begin{array}{l}\text { 4. Khi phải đi đâu đó xa nhà hoặc đi du lịch, ông/bà có khi nào quên mang theo } \\
\text { thuốc L-T4 không? }\end{array}$ & Có & Không \\
\hline 5. Ngày hôm qua, ông/bà có quên uống thuốc L-T4 không? & Có & Không \\
\hline 6. Khi cảm thấy bình thường,ông/bà có tự ý bỏ thuốc L-T4 mà chưa hỏi bác sĩ không? & Có & Không \\
\hline 7. Ông/ bà có thây việc dùng thuốc L-T4 hàng ngày bất tiện/ phiên toái không? & Có & Không \\
\hline 8. Ông/ bà có thấy việc phải nhớ uống thuốc L-T4 hàng ngày khó khăn không? & Có & Không \\
\hline
\end{tabular}

Mỗi câu hỏi có hai giá tri: có và không. Mỗi câu trả lời "có" tính là 0 điểm. Mỗi câu trả lời "không" tính là 1 điểm. Điểm Morisky là tổng điểm của 8 câu hỏi trên.

\subsection{Các tiêu chuẩn đánh giá}

\subsubsection{Tiêu chuẩn đánh giá TTSDT} * Phân loại mức độ TTSDT

- Tuân thủ cao: Điểm Morisky = 8 điểm điểm.
- Tuân thủ thấp: Điểm Morisky < 6 điểm.

* Phân loaí TTSDT

- Tuân thủ: Mức độ tuân thủ cao và trung bình.

- Không tuân thủ: Mức độ tuân thủ thấp.

2.5.2. Xét nghiệm chức năng tuyến giáp

Giá trị bình thường của xét nghiệm TSH và FT4 ở người cao tuổi thực hiện trên máy DxI800 tại bệnh viện Hữu Nghị là:

- TSH: 0,34 - 5,6 $\mu \mathrm{IU} / \mathrm{mL}$

- FT4: 7,86 - 14,41 pmol/L 
2.5.3. Tiêu chuẩn đánh giá đạt mục tiêu điêu trị

- Đạt mục tiêu: Bình giáp (TSH và $\mathrm{FT}_{4}$ bình thường)

- Không đạt mục tiêu gồm:

- Suy giáp rõ: TSH Tăng, $\mathrm{FT}_{4}$ Giảm

- suy giáp cận lâm sàng: TSH Tăng, $\mathrm{FT}_{4}$ bình thường

- cường giáp cận lâm sàng:TSH giảm, $\mathrm{FT}_{4}$ bình thường

- cường giáp rõ:TSH giảm, $\mathrm{FT}_{4}$ tăng[5].

a. Xử lý số liêu

- Phân tích dữ liệu được thực hiện bởi phần mềm SPSS 20.0

- Xác định các yếu tố liên quan tới TTSDT LT4 bằng phân tích hồi quy đa biến logistic.

\section{KẾT QUẢ NGHIÊN CỨU}

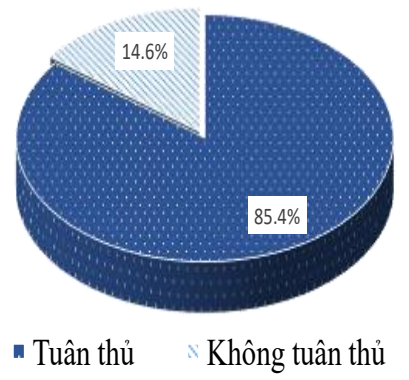

Biểu đồ 1: Đánh giá sự tuân thủ sử dụng thuốc L-T4 ở người bệnh ( $N=82)$

Nhận xét: Nghiên cứu được thực hiện trên 82 bệnh nhân SGTP cao tuổi cho thây tỷ lệ người bệnh tuân thủ sử dụng thuốc L-T4 chiếm 85,4\%.

Bảng 2: Hành ví sử dụng thuốc của bệnh nhân $(N=82)$

\begin{tabular}{|c|c|c|}
\hline $\begin{array}{c}\text { Hành vi sứ dung thuốc của } \\
\text { bệnh nhân }\end{array}$ & $\begin{array}{c}\text { SL } \\
\text { (n) }\end{array}$ & $\begin{array}{c}\text { TL } \\
\text { (\%) }\end{array}$ \\
\hline Quên uống thuốc & 7 & 8,5 \\
\hline Hai tuần qua, đã quên uống thuốc & 3 & 3,7 \\
\hline Ngưng thuốc vì cảm thấy khó chịu & 6 & 7,3 \\
\hline Quên mang thuốc khi đi xa & 12 & 14,6 \\
\hline Hôm qua đã uống thuốc đây đủ & 81 & 98,8 \\
\hline Ngưng thuốc khi thấy bình thường & 1 & 1,2 \\
\hline Phiến phức khi dùng thuốc lâu dài & 25 & 30,5 \\
\hline Khó khăn khi phải nhớ thuốc & 25 & 30,5 \\
\hline
\end{tabular}

Nhân xét. Các hành vi không tuân thủ sử dụng thuốc L-T4 của bệnh nhân chủ yếu là:khi phải nhớ uống thuốc đầy đủ hằng ngày $(30,5 \%)$, cảm thấy phiền phức khi phải uống thuốc lâu dài $(30,5 \%)$ và quên mang thuốc khi đi xa $(14,6 \%)$.

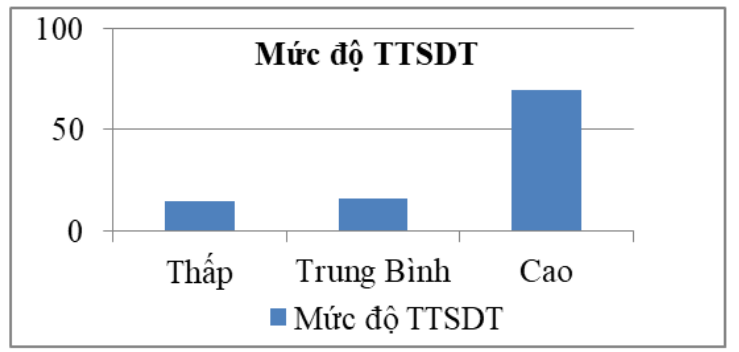

Biểu đồ 2: Đánh giá mức độ tuân thủ sử dung thuốc $(N=82)$

Nhân xét: Các bênh nhân phần lớn tuân thủ sử dụng thuốc L-T4 ở mức độ cao với 69,5\%. Có 14,6\% người bệnh không tuân thủ.

Bảng 3. Môii liên quan giữa TTSDT với các đặc điểm của bệnh nhân(N=82)

\begin{tabular}{|c|c|c|c|c|c|}
\hline \multirow{2}{*}{\multicolumn{2}{|c|}{ Yếu tố liên quan }} & \multicolumn{2}{|c|}{ Đánh giá tuân thủ } & \multirow{4}{*}{$\begin{array}{c}\text { OR (95\%CI) } \\
1 \\
0,3(0,1-1,1) \\
\end{array}$} & \multirow{4}{*}{$\begin{array}{c}\mathbf{p} \\
0,07\end{array}$} \\
\hline & & Không & Có & & \\
\hline \multirow{2}{*}{ Tuổi } & $60-70$ & $3(7,32)$ & $38(92,68)$ & & \\
\hline & $\geq 70$ & $9(21,95)$ & $32(78,05)$ & & \\
\hline \multirow{2}{*}{ Giới } & Nữ & $11(15,94)$ & $58(84,06)$ & 1 & \multirow{2}{*}{0,45} \\
\hline & Nam & $1(7,69)$ & $12(92,31)$ & $2,3(0,3-19,3)$ & \\
\hline \multirow{2}{*}{$\begin{array}{c}\text { Trình độ học } \\
\text { vấn }\end{array}$} & Dưới ĐH & $6(66,7)$ & $3(33.3)$ & 1 & \multirow{2}{*}{0,002} \\
\hline & $\mathrm{DH}$, sau $\mathrm{OH}$ & $19(26.0)$ & $54(74.0)$ & $11,8(2,6-54,3)$ & \\
\hline \multirow{3}{*}{$\begin{array}{l}\text { Thời gian mắc } \\
\text { bệnh (năm) }\end{array}$} & $\leq 5$ & $7(21,21)$ & $26(78,79)$ & 1 & \multirow{3}{*}{$\begin{array}{l}0,33 \\
0,22\end{array}$} \\
\hline & $5-10$ & $3(11,54)$ & $23(88,46)$ & $2,1(0,5-8,9)$ & \\
\hline & $\geq 10$ & $2(8,70)$ & $21(91,30)$ & $2,8(0,5-15,1)$ & \\
\hline \multirow{2}{*}{$\begin{array}{l}\text { Số loại thuốc } \\
\text { sứ dụng }\end{array}$} & $\leq 5$ & $7(12,28)$ & $50(87,72)$ & 1 & \multirow{2}{*}{0,36} \\
\hline & $>5$ & $5(20,00)$ & $20(80,00)$ & $0,6(0,2-2,0)$ & \\
\hline \multirow{2}{*}{$\begin{array}{c}\text { Số bệnh đồng } \\
\text { mắc }\end{array}$} & $\leq 2$ & $5(11,90)$ & $37(88,10)$ & 1 & \multirow{2}{*}{0,47} \\
\hline & $>2$ & $7(17,50)$ & $33(85,37)$ & $0,6(0,2-2,2)$ & \\
\hline \multirow{2}{*}{$\begin{array}{c}\text { Mục tiêu điều } \\
\text { trị }\end{array}$} & Không đạt mục tiêu & $6(33,33)$ & $12(66,67)$ & 1 & \multirow{2}{*}{0,02} \\
\hline & Đạt mục tiêu & $6(9,38)$ & $58(90,63)$ & $4,8(1,3-17,6)$ & \\
\hline
\end{tabular}

Nhận xét: Các yếu tồ liên quan đến TTSDT có ý nghĩa thống kê $(p<0,05)$ là: Trình độ học vấn và mục tiêu điều trị. 


\section{BÀN LUÂ̂N}

Sự tuân thủ sử dụng thuốc L-T4 của người bệnh

* Tỉ lệ bệnh nhân TTSDT trong nghiên cứu của chúng tôi chiếm tỉ lệ cao với 85,4\% (15,9\% tuân thủ trung bình và $69,5 \%$ tuân thủ cao). Có 14,6\% số bệnh nhân không TTSDT. Kết quả này tương đồng với nghiên cứu của Cappelli C[2] và Kradeep Kumar [6] với báo cáo tuân thủ $87 \%$ và $90,4 \%$.

* Các hành vi không TTSDT của bệnh nhân chủ yếu là: phải nhớ uống thuốc đầy đủ hằng ngày $(30,5 \%)$ và cảm thấy phiền phức khi phải uống thuốc lâu dài (30,5\%). Điều này được lý giải do bệnh nhân phải điêuu trị thuốc hàng ngày, điều trị kéo dài, điêu trị suốt đời nên có thể có tâm lý mệt mỏi, chán nản khi thực hiện việc uống thuốc L-T4. Tình trạng quên mang thuốc khi đi chơi, du lịch có tỉ lệ đứng thứ 3 là 14,6\%, có thể do thời điểm đó có quá nhiều mối quan tâm khác làm bệnh nhân quên thuốc.

* Các yêu tố liên quanđến tuân thủ sử dụng thuốc

- Tuổi: Nhóm bệnh nhân trên 70 tuổi có khả năng TTSDT kém hơn nhóm 60-70 tuổi là 70\%. Mối tương quan giữa tuổi và thực trạng TTSDT là không có ý nghĩa thống kê với $p>0,05$. Kết quả này phù hợp với thực tế vì người có tuổi cao thì trí nhớ giảm sút, hay quên, phụ thuộc con cháu trong việc đưa đi khám định kỳ. Do vậy mà sự quan tâm, giám sát, nhắc nhở, hỗ trợ của người thân là hết sức quan trọng đối với việc TTSDT ở bệnh nhân cao tuổi.

- Giới: Bệnh nhân nam có khả năng TTSDT LT4 gấp 2,3 lần các bệnh nhân nữ. Mối tương quan này là là không có ý nghĩa thống kê với $p>0,05$.

- Trình độ học vấn: Nhóm bệnh nhân có trình độ học vấn đại học và sau đại học có khả năng tuân thủ sử dụng thuốc tốt hơn nhóm dưới đại học 11,8 lần. Mối tương quannàycó ý nghĩa thống kê với $p=0,002$. Điều này cho thây, các bệnh nhân có trình độ học vấn cao có nhiều kiến thức về bệnh suy giáp, nên có chế độ ăn, chế độ tập luyện, sử dụng các loại đúng theo hướng dẫn của nhẩn viên y tế và khuyến cáo của nhà sản suất. Nên tỉ lệ TTSDT của họ tốt hơn.

- Thời gian điều trị SG không có sự tương quan với tuân thủ sử dụng $L-T 4$ với $p>0,05$. Tuy nhiên, các bệnh nhân có thời gian điều trị càng cao thì khả năng TTSDT L-T4 càng tốt.

- Số loại thuốc và số bệnh đồng mắc đều không có sự tương quan với tuân thủ sử dụng L-
T4 với $p>0,05$. Những bệnh nhân sử dụng $>5$ loại thuốc có tî lệ TTSDT giảm 40\% so với nhóm dùng $\leq 5$ loại thuốc. Do khi uống nhiều loại thuốc, vào nhiều thời điểm khác nhau, bệnh nhân có xu hướng dễ quên thuốc hơn. Tỉ lệ bệnh nhân có $>2$ bệnh đồng mắc có tỉ lệ TTSDT kém hơn nhóm còn lại $40 \%$.

- Mục tiêu điều trị có sự tương quanvới tình trạng TTSDT L-T4 của người bệnh với $\mathrm{p}<0.05$. Ở nhóm đạt mục tiêu có tî lệ TTंSDT gấp 4,8 lần nhóm không đạt mục tiêu điều trị ( $\mathrm{OR}=4,8$, $95 \% \mathrm{CI}: 1,3-17,6)$. Điều này có nghĩa là các bệnh nhân có kết quả điều trị tốt thì khả năng tuân thủ sử dụng thuốc tốt.

\section{KẾT LUẬN \& KIẾN NGH!}

- Tỷ lệ tuân thủ sử dụng thuốc L-T4trên bệnh nhân SGTP cao tuổi điều trị ngoại trú tại Bệnh viện Hữu Nghị chiếm 85,4\%.

- Các yếu tố liên quan đếntuân thủ sử dụng thuốc L-T4: Trình độ học vấn và mục tiêu điều trị.

- Kiến nghị: Nâng cao nhận thức của bệnh nhân về bệnh suy giáp thông qua hướng dẫn của nhân viên y tế, tham khảo các tài liệu, sách báo, tạp trí, internet về bệnh suy giáp.

\section{TÀI LIẸU THAM KHẢO}

1. Mateo RCI, Hennessey JV. Thyroxine and treatment of hypothyroidism: seven decades of experience. Endocrine. 2019; 66(1): 10-17. doi:10.1007/s12020-019-02006-8.

2. Cappelli C, Castello $R$, Marini F, et al. Adherence to Levothyroxine Treatment Among Patients With Hypothyroidism: A Northeastern Italian Survey. Front Endocrinol (Lausanne). 2018;9:699. Published 2018 Nov 23. doi:10.3389/fendo.2018.00699. PMID: 30532737;

3. Wilmar M.Wiersinga (2004), Adult Hypothyroidism, Endocrinology. Volume 2(14th edition), tr. 1491-1506.

4. Morisky DE, Ang A, Krousel-Wood M, Ward HJ. Predictive validity of a medication adherence measure in an outpatient setting. J Clin Hypertens (Greenwich). 2008 May; 10(5):348-54. doi: 10.1111/ j.1751-7176.2008.07572.x. PMID: 18453793;

5. Somwaru LL, Arnold AM, Joshi N, Fried LP, Cappola AR. High frequency of and factors associated with thyroid hormone over-replacement and under-replacement in men and women aged 65 and over. J Clin Endocrinol Metab. 2009;94(4):1342-1345. doi:10.1210/jc.2008-1696.

6. Kumar P, Khandelwal D, Mittal S, Dutta D, Kalra S, Katiyar P, Aggarwal V. Knowledge, Awareness, Practices and Adherence to Treatment of Patients with Primary Hypothyroidism in Delhi. Indian J Endocrinol Metab. 2017 MayJun;21(3):429-433.

10.4103/ijem.IJEM_49_17. PMID: 28553600; 